\title{
Analysis of Pesticide Residues in Curry Leaves and Red Gram in Tirupati Region, Chittoor by Gas Chromatography
}

\author{
Vineela, Ramya Kuber B*
}

Institute of Pharmaceutical Technology, Sri Padmavati Mahila Viswavidyalayam, Tirupati, Andhra Pradesh, India

\begin{abstract}
Medicine is food and food is medicine" is the best way to describe on how the ailments were cured by using the plants during the ancient period of time. The "Magical plant of Indian Spice" (Murraya koenigii) has served human kind not only as food enhancer but also serve as village or folk medication to cure many disorders, the tribal communities has used many parts of the Murrayakoenigiito cure them diseases. Pigeonpea [Cajanuscajan(L.) Millsp.]Pigeon pea (Arhar) commonly known as Red gram or tur is a very old crop in India. The term 'Pigeon pea' was coined in Barbados. The present study is to determine the pesticide residue levels in Curry leaf (Murraya koenigii) and Red gram (Peagion Pea) in Tirupati, Chittoor region.
\end{abstract}

Keywords-Curry leaves, Gas Chromatogrpahy, Pesticide Standards, Red Gram.

\section{INTRODUCTION}

Murraya koenigii, commonly known as curry leaf or karivepaku or Kari patta in Indian dialects, belonging to Family Rutaceae which represent more than 150 genera and 1600 species (Gabriel Charles and Vincent Onuegbu, 2014). Fresh leaves, dried leaf powder, and essential oil are widely used for flavoring soups, curries, fish and meat dishes, eggs dishes, traditional curry powder blends, seasoning and ready to use other food preparations (Gupta et al.,1971) . It is called as 'Magical plant of Indian spice'. It is not only used as food enhancing purpose but also shows medication for many diseases(Surbhisinghal and meenakshibatt, 2016). The essential oil is also utilized by soap and cosmetic aromatherapy Industry. Peagion Pea which belongs to the family Fabaceae, is commonly known as Red gram ,in Andhra pradesh we called as Kandi pappu, other names like Tur, arhar, Dhal etc. This is very old crop and major cultivated crop in India (Gowda et al., 2011). These crops were contaminated with pesticides, not only these two, almost all crops are contaminated with pesticide which are sprayed on crops. So the present work is aimed to determine the pesticide residue levels in Curry leaves and Red gram in Tirupati region, Chittoor by using Gas Chromatography. Pesticides which are determined in this article are chlorpyrifos, profenofos, triazophos. Chlorpyrifos is a broad spectrum organophosphate pesticide, kills the insects and worms on crops, animals, buildings(Mackay et al.,2014). Profenofos is a non-systemic broad spectrum, foliar insecticide and acaricide. It shows excellent translaminar action and effective against chewing and sucking insects, mites on cotton, rice, maize, sugar beet, soybeans, vetables, tobacco, oil seeds etc., (Madhulika kushwaha et al. 2016). Triazophos is a broad spectrum, non systematic contact organosphosphorus pesticides used to control pests, insects, acarids, some nematodes in okra, cotton, maize, rice paddies etc.,(Aungpdradit et al. 2007).Pesticide residues in curry leafs was determined in different markets of Andhra Pradesh \& Telangana by using LC-MS/MS.(Priyadarshini et al., 2017)

\section{MATERIALS AND METHODS:}

Market samples of curry leaf and Red gram were collected from local market Tirupati region Chittoor. Samples were extracted for pesticide residues following the validated QuEChERS method to give best results.

\subsection{Sample extraction:}

Curry leaf samples were analyzed for pesticide residues following the AOAC official method (QuEChERS) which is the best method in the laboratory. The samples were collected from local Tirupati market in polythene bag. Curry leaves was homogenized separately with robot coupe Blixer. $5 \mathrm{~g}$ of sample was weighed and taken in $50 \mathrm{ml}$ centrifuge tube and $10 \mathrm{ml}$ distilled water, $15 \mathrm{ml}$ acetonitrile was added to sample tube. The sample was homogenized at 14000-15000rpm for 2-3 min. $6 \mathrm{~g}$ sodium chloride was added to sample, mixed thoroughly by shaking gently followed by centrifugation for $3 \mathrm{~min}$ at $2500-3000 \mathrm{rpm}$ to 
separate the organic layer. The top organic layer of about $9 \mathrm{ml}$ was taken into the $15 \mathrm{ml}$ centrifuge tube and added with $1.4 \mathrm{~g}$ magnesium sulphate to remove the moisture content and added $1 \mathrm{~g}$ PSA sorbent (for dispersive solid phase dSPE cleanup), and $0.05 \mathrm{~g}$ of GCB (Graphitized Carbon Black) shaken gently followed by centrifuge for $2 \mathrm{~min}$ at 2500rpm. The sample tube was vortexed for $30 \mathrm{sec}$ then followed by centrifuge for $5 \mathrm{~min}$ at 2500-3000rpm. $2 \mathrm{ml}$ supernant layer was transferred into $10 \mathrm{ml}$ tube for evaporation using water bath and reconstitute with $1 \mathrm{ml}$ of nhexane. Now pour it in GC vials and inject it in GC having FPD detector. Same procedure were followed for Red gram. Weigh individual reference standard around $15 \mathrm{mg}$ in $25 \mathrm{ml}$ volumetric flask. Dissolve in n-hexane for standards to be used on GC-FPD and adjust to 500ppm removing required quantity and making up to $25 \mathrm{ml}$. The working standards are prepared by serial dilutions from stock solution i.e $0.1,0.25$, $0.5,0.75,1 \mathrm{ppm}$ by suitable solvent $\mathrm{n}$-hexane and used as standard check in analysis linearity studies(Swarupa Rani et al., 2016).

\section{INSTRUMENT ANALYSIS}

The chromatographic system was SHIMADZU AOC-20S 2010 plus, equipped with an Auto sampler and EB Column $_{1}$ $0.25 \mathrm{~mm} \times 0.25 \mu \mathrm{m}, 30 \mathrm{~m}$ length. The determination of pesticide residue analysis was carried out by following conditions - Injection volume $1 \mu \mathrm{l}$, Run time 20min, Detector Flame photometric detector(FPD), Injection temperature $260^{\circ} \mathrm{c}$, Column flow $6 \mathrm{ml} / \mathrm{min}$, column programming $60^{\circ} \mathrm{c}$, Column $\mathrm{EB}_{1}$, Detector, temperature $280^{\circ} \mathrm{c}$ the run time will change for standards.

\section{RESULTS AND DISCUSSION}

The pesticide residue levels are calculated by following formula:

Residues $(\mu \mathrm{g} / \mathrm{g})$ :

$\frac{\text { height or area of sample }}{\text { height or area of the sample }} \times \frac{\mu \text { of sample injected }}{\mu \text { l of the standard injected }} \times$ conc. of standard / weight of sample $\mathrm{x}$ final volume

- equation (1)

Pesticides are applied to Vegetables, leafy vegetables, fruits and various crops at various stages of cultivation and for protection against a range of pests during harvest before they become available to consumer.

To ensure the safety of food for consumers and regulate international trade, legislations such as European Union directives has established maximum residue limits for pesticides in food stuff. Thorough monitoring of pesticide residues is crucial for proper risk assessment of human exposure through food.

Compared with other available methods, the QuEchERS method is believe to give the best results.

\subsection{GC determination of pesticide standards:}

The pesticide residue was identified by comparing its retention time $(\mathrm{Rt})$. The quantitative determination was carried out with help of a calibration curve. A good linearity was established by a correlation coefficient $\left(R^{2}\right)$ value (0.97).

Correlation coefficient is a statistical tool used to measure the degree of this type relationship and here a high correlation value (A value very close to1.0) indicates a high level linear relationship between the concentration of standards and peak area. For quantification an external calibration curve with four different concentration matrix matching were made.

The standards are dissolved in n-hexane it was injected in GC as an blank. In blank chromatogram we observed only one peak i.e solvent peak as shown in Fig.1

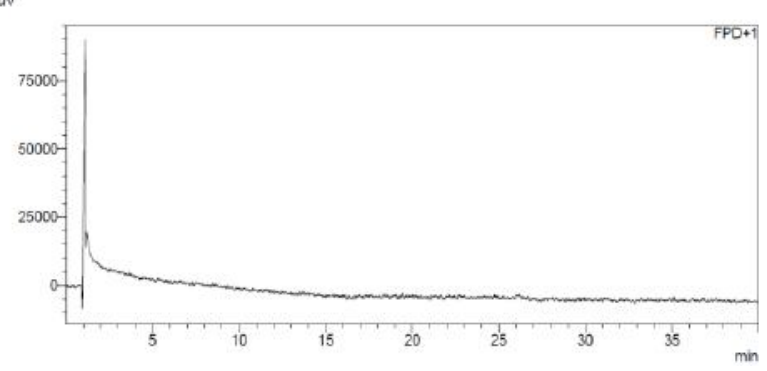

Fig.1: The blank chromatogram with solvent peak

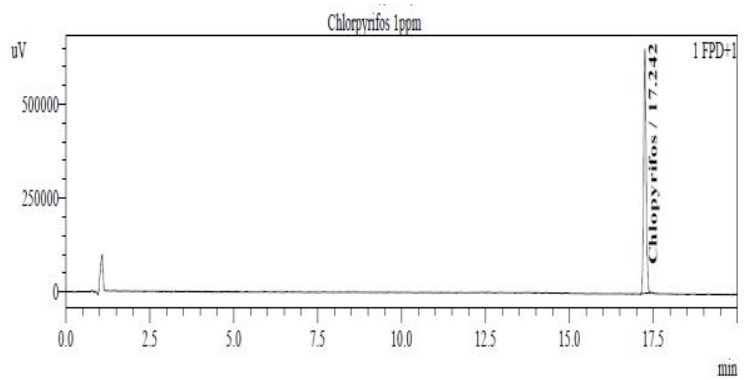

Fig.2: The Standard chromatograms of Chlorpyrifos

\begin{tabular}{|l|l|l|l|l|}
\hline Peak & $\begin{array}{l}\text { Retention } \\
\text { time }\end{array}$ & Area & Height & Name \\
\hline 1 & 17.242 & $\begin{array}{l}338391 \\
8\end{array}$ & 649767 & $\begin{array}{l}\text { Chlorpyr } \\
\text { ifos }\end{array}$ \\
\hline $\begin{array}{l}\text { Tota } \\
1\end{array}$ & & $\begin{array}{l}338391 \\
8\end{array}$ & 649767 & \\
\hline
\end{tabular}

4.1.1 Linearity for the Chlorpyrifos: 
The linearity was established by analysing standard solutions of the insecticides at five concentrations. The concentrations were $0.1,0.25,0.5,0.75,1 \mu \mathrm{g} / \mathrm{ml}$. Graphs were constructed from the GC chromatograms based on the average peak area of the signal response versus the concentration plot of the analytes. The parameters such as the slope of the regression line, $y$-intercept and the correlation coefficient were evaluated.

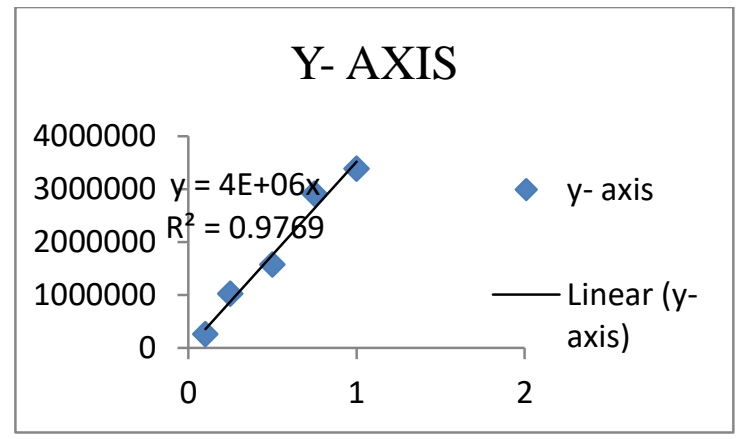

Fig.3: Linearity of chloropyrifos

Table : 1

\begin{tabular}{|l|l|l|}
\hline Sl no. & Concentration $(\mu \mathrm{g} / \mathrm{ml})$ & Area \\
\hline 1 & 0.1 & 256874 \\
\hline 2 & 0.25 & 1022717 \\
\hline 3 & 0.5 & 1572715 \\
\hline 4 & 0.75 & 2910537 \\
\hline 5 & 1 & 3383918 \\
\hline 6 & Slope & $4 \mathrm{E}$ \\
\hline 7 & Y-intercept & $06 \mathrm{x}+4 \mathrm{E}$ \\
\hline 8 & Correlation coefficient & 0.976 \\
\hline
\end{tabular}

The linearity of the method was determined at five concentration levels ranging from 0.1-1ppm for Chlorpyrifos. The regression line equation for Chlorpyrifos was $\mathrm{Y}=4 \mathrm{E}+06 \mathrm{X}$ and the regression coefficient value was 0.967 respectively.

The regression data for the calibration curve showed good linear relationship over

a concentration range $0.1-1 \mathrm{ppm}$ for Chlorpyrifos with respect to peak area.

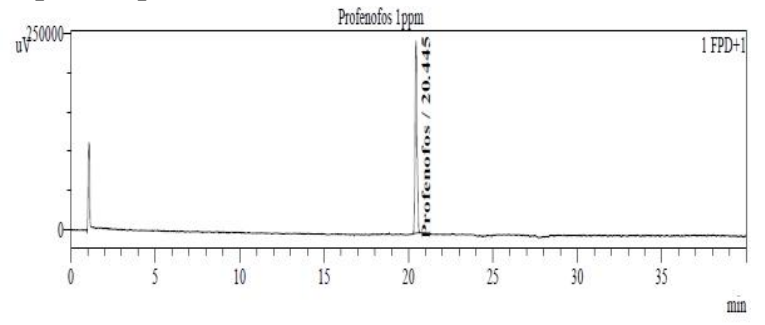

Fig.4: standard chromatogram of profenofos

\begin{tabular}{|l|l|l|l|l|}
\hline Peak & $\begin{array}{l}\text { Retention } \\
\text { time }\end{array}$ & Area & Height & Name \\
\hline 1 & 20.445 & 1985369 & 243885 & Profenofos \\
\hline Total & & 198569 & 243885 & \\
\hline
\end{tabular}

\subsubsection{Linearity for Profenofos:}

The linearity of the method was determined at five concentration levels ranging from 0.1-1 ppm for profenofos. The regression line equation for Profenofos was $\mathrm{Y}=2 \mathrm{E}+06 \mathrm{X}$ and the regression coefficient value was 0.994 respectively.

The regression data for the calibration curve showed good linear relationship over a concentration range $0.1-1 \mathrm{ppm}$ for Profenofos with respect to peak area.

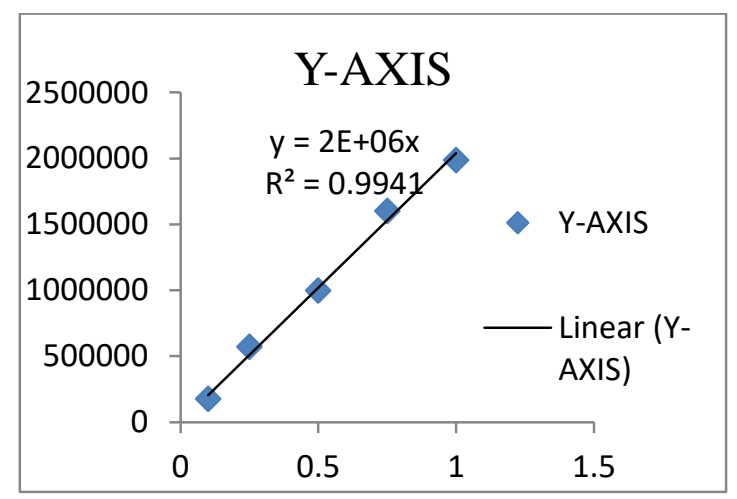

Fig.5: Linearity of profenofos

Table : 2

\begin{tabular}{|l|l|l|}
\hline Sl no & Concetration $(\mu \mathrm{l} / \mathrm{ml})$ & Area \\
\hline 1 & 0.1 & 175354 \\
\hline 2 & 0.25 & 570827 \\
\hline 3 & 0.5 & 997618 \\
\hline 4 & 0.75 & 1600129 \\
\hline 5 & 1 & 1985369 \\
\hline 6 & Slope & $2 \mathrm{E}$ \\
\hline 7 & y-intercept & $2 \mathrm{E}+06 \mathrm{X}$ \\
\hline 8 & Correlation coefficient & 0.994 \\
\hline
\end{tabular}

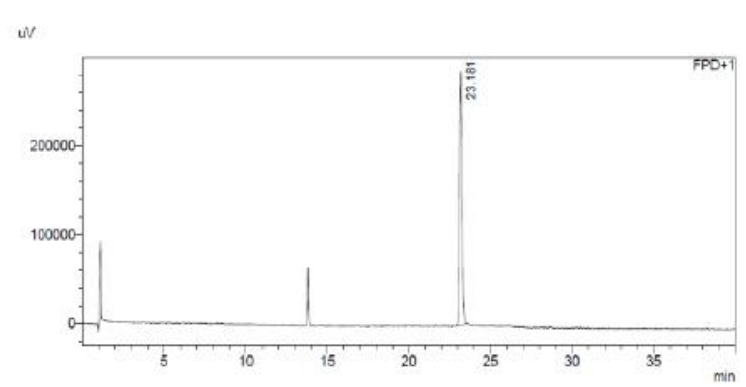

Fig.6: Standard chromatogram for triazofos 


\begin{tabular}{|l|l|l|l|l|}
\hline Peak & $\begin{array}{l}\text { Retention } \\
\text { time }\end{array}$ & Area & Height & Name \\
\hline 1 & 23.181 & 3032415 & 284816 & Triazofos \\
\hline Total & & 3032415 & 284816 & \\
\hline
\end{tabular}

\subsubsection{Linearity for Triazofos :}

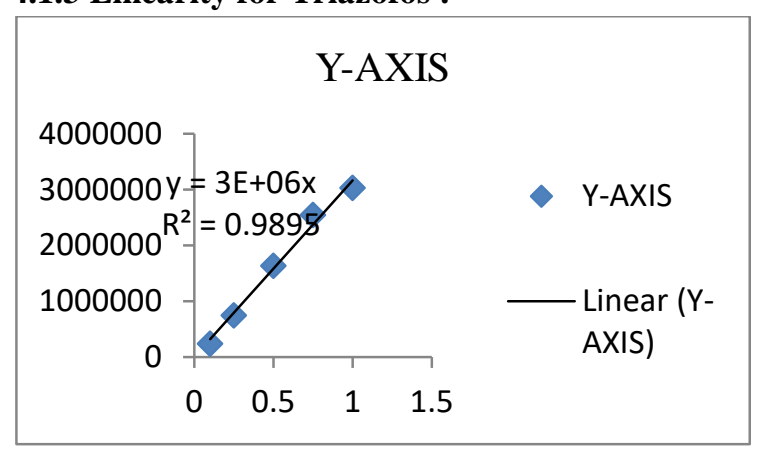

Fig.7: Linearity of triazofos

Table : 3

\begin{tabular}{|l|l|l|}
\hline S1 no & Concentration & Area \\
\hline 1 & 0.1 & 237780 \\
\hline 2 & 0.25 & 743255 \\
\hline 3 & 0.5 & 1634619 \\
\hline 4 & 0.75 & 2545213 \\
\hline 5 & 1 & 3032415 \\
\hline 6 & Slope & $3 \mathrm{E}$ \\
\hline 7 & y-intercept & $06 \mathrm{X}+3 \mathrm{E}$ \\
\hline 8 & Correlation coefficient & 0.989 \\
\hline
\end{tabular}

The linearity of the method was determined at five concentration levels ranging from $0.1-1 \mathrm{ppm}$ for Triazofos. The regression line equation for Triazofos was $\mathrm{Y}=3 \mathrm{E}+06 \mathrm{X}$ and the regression coefficient value was 0.989 respectively.

The regression data for the calibration curve showed good linear relationship over a concentration range $0.1-1 \mathrm{ppm}$ for Triazofos with respect to peak area.

\subsection{Chromatograms of curry leaves samples}

\subsubsection{Unwashed curry leaves}

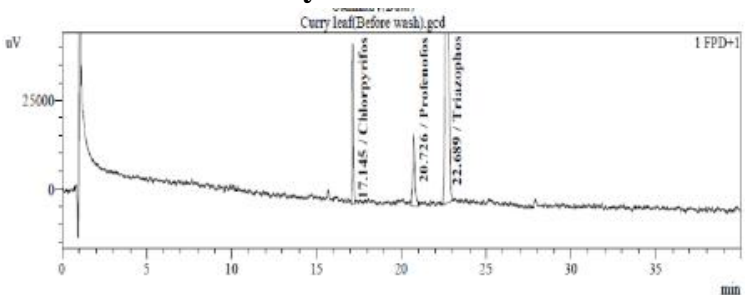

Fig.8: Sample chromatogram of unwashed curry leaves

\begin{tabular}{|l|l|l|l|l|}
\hline Sample & $\begin{array}{l}\text { Detected } \\
\text { pesticide }\end{array}$ & $\begin{array}{l}\text { Retentio } \\
\text { n time }\end{array}$ & Area & Height \\
\hline $\begin{array}{l}\text { Unwashe } \\
\text { d curry } \\
\text { leaves }\end{array}$ & $\begin{array}{l}\text { Chlorypyrifo } \\
\mathrm{s}\end{array}$ & 17.145 & 233414 & 45295 \\
\hline & Profenofos & 20.726 & 191030 & 20284 \\
\hline & Triazofos & 22.697 & $\begin{array}{l}457426 \\
5\end{array}$ & $\begin{array}{l}45256 \\
2\end{array}$ \\
\hline
\end{tabular}

Observation:

The Curry leaf samples were analyzed in GC for the presence of pesticide residue to know the different pesticides eluted in washed curry leaves samples, were compared with standard chromatograms with their retention time i.e Chlorpyrifos RT was 17.242, Profenofos RT was 20.445 and Triazofos RT was 23.181. Then the presence of pesticide residue levels are compared with standard MRLs fixed by prevention of food Adulteration Act (PFA), Govt. Of India was followed by EUROPEAN UNION MRLs.

In Unwashed curry leaves the Chlorpyrifos was found to be $0.069 \mathrm{mg} / \mathrm{kg}$, Profenofos was found to be $0.096 \mathrm{mg} / \mathrm{kg}$ and Triazofos was found to be $1.508 \mathrm{mg} / \mathrm{kg}$. In this present study we observed that Triazofos was detected above the MRLs i.e is $1.508 \mathrm{mg} / \mathrm{kg}$ respectively. But it should be $0.01 \mathrm{mg} / \mathrm{kg}$ as per EUROPEAN UNION (EU).

\subsubsection{Washed curry leaves:}

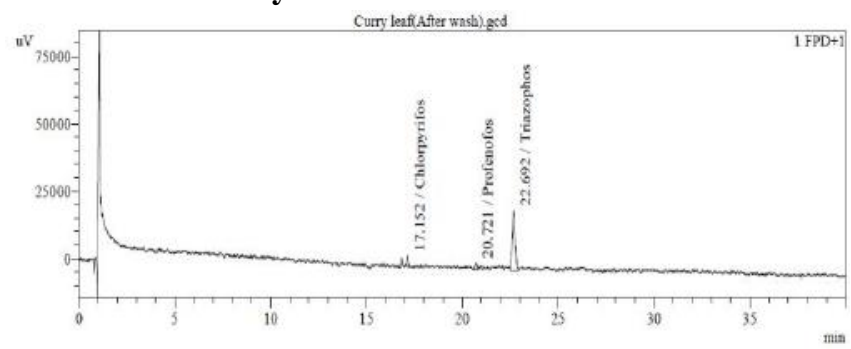

Fig.9: Sample chromatogram of washed curry leaves

\begin{tabular}{|l|l|l|l|l|}
\hline Sample & $\begin{array}{l}\text { Detected } \\
\text { pesticide }\end{array}$ & $\begin{array}{l}\text { Retention } \\
\text { time }\end{array}$ & Area & Height \\
\hline $\begin{array}{l}\text { Washed } \\
\text { curry } \\
\text { leaves }\end{array}$ & Chlorypyrifos & 17.152 & 23422 & 4212 \\
\hline & Profenofos & 20.721 & 20501 & 2642 \\
\hline & Triazofos & 22.692 & 240020 & 22350 \\
\hline
\end{tabular}

Observation:

In washed Curry leaves the Chlorpyrifos was found to be $0.0069 \mathrm{mg} / \mathrm{kg}$, Profenofos was found be $0.01 \mathrm{mg} / \mathrm{kg}$ and 
Triazofos $0.079 \mathrm{mg} / \mathrm{kg}$. So, in washed curry leaves the pesticide residue levels are decreased when compared with unwashed curry leaves residue levels (Chlorpyrifos was $0.069 \mathrm{mg} / \mathrm{kg}$, Profenofos was $0.096 \mathrm{mg} / \mathrm{kg}$ and Triazofos was $1.508 \mathrm{mg} / \mathrm{kg}$ ). so water might have a capacity to minimize the pesticide residues.

\subsubsection{Curry leaves soaked in salt water:}

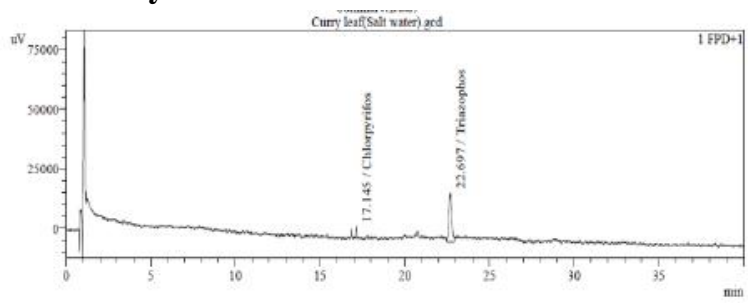

Fig.10: sample chromatogram of curry leaves soaked in salt water

\begin{tabular}{|l|l|l|l|l|}
\hline Sample & $\begin{array}{l}\text { Detected } \\
\text { pesticide }\end{array}$ & $\begin{array}{l}\text { Retention } \\
\text { time }\end{array}$ & Area & Height \\
\hline $\begin{array}{l}\text { Curry } \\
\text { leaves } \\
\text { soaked } \\
\text { with } \\
\text { salt } \\
\text { water }\end{array}$ & Chlorypyrifos & 17.145 & 21996 & 5042 \\
\hline & Profenofos & $\begin{array}{l}\text { Not } \\
\text { detected }\end{array}$ & - & \\
\hline & Traizofos & 22.697 & 228521 & 20446 \\
\hline
\end{tabular}

Observation:

In this sample, the Chlorpyrifoswas found to be 0.0065 $\mathrm{mg} / \mathrm{kg}$, Triazofos $0.075 \mathrm{mg} / \mathrm{kg}$ and Profenofos was not detected. The Curry leaves were soaked in salt water about half hour, the pesticide residue levels was reduced (Chlorpyrifos was $0.0065 \mathrm{mg} / \mathrm{kg}$, Triazofos $0.075 \mathrm{mg} / \mathrm{kg}$ and Profenofos was not detected) when compared with both washed(Chlorpyrifos was $0.0068 \mathrm{mg} / \mathrm{kg}$, Profenofos was $0.01 \mathrm{mg} / \mathrm{kg}$ and Triazofos was $0.079 \mathrm{mg} / \mathrm{kg}$ ) and unwashed (Chlorpyrifos was $0.0069 \mathrm{mg} / \mathrm{kg}$, Profenofos was $0.096 \mathrm{mg} / \mathrm{kg}$ and Triazofos was $1.508 \mathrm{mg} / \mathrm{kg}$ ) curry leaves samples. In soaked curry leaves the Profenofos was not detected, so the salts may have capacity to remove pesticide after soaking curry leaves in salt water and it may be advisable to the people.

\subsection{The Chromatograms of Red gram sample was carried out by GC:}

Major cultivation crops in pulses are red gram. Red gram is found to be contaminated with more number of pesticides the most commonly detected pesticide in cereals and pulses is Chlorpyrifos which has effect on health and safety of mammals. Poisoning with this compound can effect the central nervous system, cardiovascular and respiratory system elucidated the percent contamination of pesticides in the pulses.

\subsubsection{Unwashed red gram:}

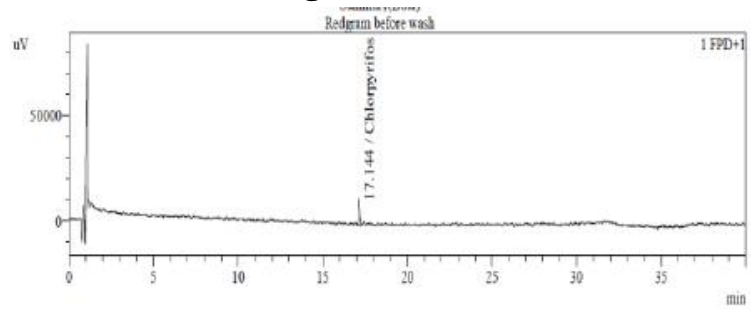

Fig.11: chromatogram of unwashed red gram sample

\begin{tabular}{|l|l|l|l|l|}
\hline Sample & $\begin{array}{l}\text { Detected } \\
\text { pesticide }\end{array}$ & $\begin{array}{l}\text { Retention } \\
\text { time }\end{array}$ & Area & Height \\
\hline $\begin{array}{l}\text { Washed } \\
\text { red gram }\end{array}$ & Chlorpyrifos & 17.144 & 74396 & 13069 \\
\hline
\end{tabular}

Observation:

In Unwashed red gram the Chlorpyrifos was found to be $0.024 \mathrm{mg} / \mathrm{kg}$. It was within the limits according to European union (EU) i.e Chlorpyrifos MRL is $0.05 \mathrm{mg} / \mathrm{kg}$

\subsubsection{Washed red gram:}

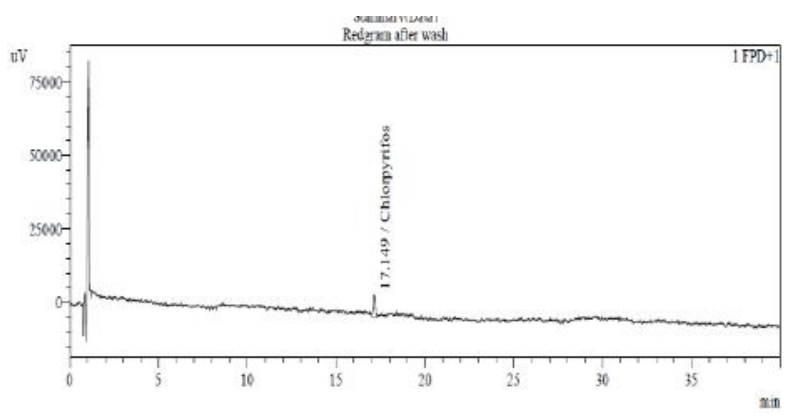

Fig.12: sample chromatogram of washed red gram

Observation:

In washed red gram the Chlorpyrifos was found to be $0.014 \mathrm{mg} / \mathrm{kg}$.it was with in the limits according to European union(EU). The Chlorpyrifos was decreased in washed red gram when compared to unwashed red gram sample i.e about $0.02 \mathrm{mg} / \mathrm{kg}$, in washed with tap water the residue levels was $0.014 \mathrm{mg} / \mathrm{kg}$. 


\section{REFERENCES}

[1] Gabriel Charles Disegha, Vincent Onuegbulzionworu. Antifungal activities of curry leaf (murraya koengii) Extract on some selected fungi. 2014. Chemistry and Materials Research, 6(11), 1-7.

[2] Gupta GL and Nigam SS. 1971 chemical examination of leaves of Murrayya koenigii, Planta Med, 19 83-86.

[3] Surbsighal and Dr. Meenakshi bhatt. 2016, A Review on Murraya koenigii(curry plant) - Methi neem. World journal of pharmacy and pharmaceutical sciences, 5 : 397-408.

[4] Gowda CLL, Saxena KB, Srivastava RK, Upadhyaya HD, 2011 Pigeonpea: From an orphan to leader in food legumes in biodiversity in agriculture, domestication evolution and sustainability 15, 361373.

[5] Mackay D, Giesy JP, Solomon KR. 2014, Fate in the environment and long-range atmospheric transport of the organophosphorus insecticide chlorpyrifos and its oxon. Rev environment contamination toxicology, 231, 35-76.

[6] Madhulika kushwaha, shalini verma, and subhankar chatterjee. 2016. Profenofos an acetylcholinesteraseinhibiting organophosphorus pesticide a short review of its usage toxicity and biodegradation. Journal of environmental quality. 45, 1478-1489.

[7] Aungpradit T, Suthivaiyakit P, Martens D, sutthivaiyakit S, Kettrup AAF. Photo catalytic degradation of triazophos in aqueous titanium dioxide suspension.2007 Microbialresearch, 13, 146-204.

[8] Swarupa S, Shashi vemuri and Venkateswar Reddy V. 2017 Pesticide usage pattern and farmers perception in curry leaf [Murraya koeinigii(L.) sprengel]. Journal of environmental science, toxicology and food technology (IOSR-JESTFT) 11, 66-72.

[9] Priyadarshini G, Shasi Vemuri, Narendra Reddy C, Swarupa rani S.2012. Determination of Pesticide Residues in curry leaf in different markets of Andhra Pradesh and Telangana, India. International journal of environment, Agriculture and Biotechnology, 2, 101111. 